\title{
LA CORRESPONDENCIA DE DAVID CARDOSO NÚÑEZ CON EL CÓNSUL ESPAÑOL GONZÁLEZ SALMÓN
}

MARIANO ARRIBAS PALAU

La familia Cardoso era originaria de Gibraltar '. David Cardoso Núñez aparece por primera vez, que yo sepa, en la documentación española del último tercio del siglo XVIII, en un escrito que dirige el cónsul Tomás Bremond ${ }^{2}$ al marqués de Grimaldi el 27 de agosto de 1769. En este escrito Bremond informa de una queja dada por David Cardoso en relación con una injusticia que dice que se le ha hecho en Ayamonte. El cónsul español acompaña a su escrito la copia de una carta en la que se le recomienda el asunto de orden del sultán de Marruecos ${ }^{3}$. El marqués de Grimaldi responde a Tomás Bremond el 19 de septiembre, comunicándole que se harán las averiguaciones correspondientes sobre este asunto a fin de poder "tomar la providencia que corresponda en justicia" ${ }^{4}$. Efectivamente, el marqués de Grimaldi envía el mismo día 19 el escrito de Bremond al gobernador de Ayamonte, Lucas Luzy, para que a la vista de su contenido informe sobre la cuestión s.

1 De la familia Cardoso se ocupan A. I. Laredo, Les noms des Juifs du Maroc, Madrid 1978, n 1023, apartado 3, pág. 1048; y R. LouRIDo Dfaz, "Los judíos de Marruecos durante el sultanato de Siđđi Muhammad b. 'Abd Allāh (1757-1790)", en MEAH XXVI-XXVIII (1977- 1979) 327-355, 352.

2 Tomás Bremond y Linares acompañó a Jorge Juan en su embajada a Marruecos el año 1767 en calidad de secretario. Una vez firmado el tratado de paz entre España y Marruecos, Bremond quedó como cónsul general de España en Marruecos, con residencia en Larache. Véase: V. Rodriguez CaSAdo, Politica marroquí de Carlos III, Madrid 1946, págs. 95-133 y 135-179.

${ }^{3}$ En AHN. [Archivo Histórico Nacional], sección de Estado, legajo 4311, caja 1, hay un extracto de la carta, pero no he encontrado ni la carta de Bremond ni la copia de la carta de recomendación que la acompañaba, probablemente de Samuel Sumbel.

4 Así se indica a continuación del extracto citado en la nota anterior.

5 También se indica esta gestión al final del extracto citado en la nota 3, después de la nota relativa a la respuesta de Grimaldi a Bremond, citada en la nota 4. 
Lucas Luzy acusa recibo de la carta del marqués de Grimaldi y le comunica que se dispone a tomar conocimiento de la causa que se ha formado por el envío de harina efectuado por David Cardoso al puerto de Ayamonte, a su correspondiente en el mismo, Pedro Carlier. Una vez tenga el debido conocimiento del asunto, Lucas Luzy promete informar puntualmente del mismo al marqués de Grimaldi *.

Sin embargo, un año más tarde no se había resuelto la cuestión, por lo que David Cardoso se dispone a renovar sus quejas ante el soberano marroquí. Samuel Sumbel ${ }^{7}$ escribe entonces a Tomás Bremond comunicándole que no ha querido dejar a Cardoso que llevara de nuevo sus quejas a la audiencia del monarca marroquí, con la esperanza de que el cónsul español recuerde a su corte la cuestión de la partida de harina enviada por Cardoso a Ayamonte, que fue arrojada al mar, sobre la cual había escrito anteriormente Sumbel, de orden del Sultán, a Bremond. Espera Sumbel que el cónsul español se interese debidamente con la corte de España para que se haga justicia cuanto antes a Cardoso ${ }^{8}$.

Tomás Bremond envía una copia de esta carta de Sumbel al marqués de Grimaldi, con objeto de que «sirviendo al govierno de V.E., delibere lo que fuesse de su superior agrado" ".

No he encontrado más documentación sobre el caso, lo que tal vez sea indicio de que se resolviera de acuerdo con los deseos de Cardoso.

$\mathrm{Al}$ año siguiente, Tomás Bremond da cuenta al gobernador de Cádiz, Nicolás Bucareli y Ursúa ${ }^{10}$ de que el soberano marroquí ha abierto al comercio el puerto de la Mamora, al cual han empezado

' Véase la carta de Lucas Luzy al marqués de Grimaldi fechada en Ayamonte el 30 de septiembre de 1769, que se conserva original en AHN., Estado, leg. 4309, caja 2.

7 Sobre este judío marroquí puede verse M. Arribas PalaU, "Datos sobre Samuel Sumbel y sus relaciones con España", Sefarad XL (1980) 121-139.

${ }^{8}$ De esta carta, fechada el 1 de septiembre de 1770, tenemos una copia en AHN., Estado, leg. 4311, caja 2.

${ }^{9}$ La carta de Bremond está fechada en Larache el 8 de octubre de 1770. El original se conserva en AHN., Estado, leg. 4311, caja 2.

${ }^{10}$ Nicolás Bucareli y Ursúa era el cuarto hijo de Luis Bucareli Henestrosa y Ribera y de Ana María de Ursúa Laso de la Vega. Casó con su sobrina Juana Antonia Bucareli y Baeza, hija de José Miguel Bucareli y Ursúa, tercer marqués de Vallehermoso, y de Ana Antonia de Baeza y Vicentelo. Véase: A. y A. Garcia CARraffa, Diccionario Heráldico y Genealógico..., t. 19, Madrid 1925, págs. 103-105, y J. DE Atienza y NaVajas, Nobiliario español, Madrid 1954², pág. 1000. 
a acudir los comerciantes españoles. Como quiera que en el referido puerto de la Mamora no encuentra Bremond otra persona en él residente que pueda habilitar a las embarcaciones españolas las correspondientes patentes de sanidad sino "vn comerciante judío nombrado David Cardoso Núñez", lo pone en conocimiento de Nicolás Bucareli, por si le parece oportuno que se admita a los españoles la patente extendida por David Cardoso, "para alivio del comercio", pues Bremond está convencido de que, en caso contrario, los españoles dejarían de ir a traficar a la Mamora, por temor a tener que hacer la obligada cuarentena.

En relación con el estado de sanidad en Marruecos, afirma nuestro cónsul que en todos aquellos dominios no hay «noticia ni indicio de peste ni de otra enfermedad contagiosa". Por otra parte, en el supuesto de que en la Mamora ocurriera alguna novedad en materia sanitaria, Bremond se enteraría de ella en un plazo muy breve, ya que la Mamora dista de Larache solamente dos días de camino, y el propio Bremond sería el primero en avisar al gobernador de Cádiz en todo tiempo cuanto guardara relación con la salud pública, en el caso de que surgiera algún motivo que aconsejara tomar determinadas precauciones con las embarcaciones procedentes de la Mamora ".

Tan pronto como el gobernador de Cádiz recibe esta carta de Bremond, le contesta que da parte de ella al marqués de Grimaldi pidiéndole instrucciones, ya que él carece de «orden o prevención alguna en el asunto de que trata». En efecto, Nicolás Bucareli envía al marqués de Grimaldi una copia de la carta de Bremond para que resuelva lo que tenga por conveniente ${ }^{12}$. También Bremond envía directamente al marqués de Grimaldi, para su debido conocimiento, una copia de la carta que ha dirigido al gobernador de Cádiz ${ }^{13}$.

$\mathrm{Al}$ enterarse el primer ministro, marqués de Grimaldi, de este asunto, contesta a Nicolás Bucareli diciéndole que no hay inconveniente en que se admitan las patentes de sanidad expedidas por

" La carta de Tomás Bremond a Nicolás Bucareli y Ursúa está fechada en Larache el 20 de julio de 1771. De ella tenemos una copia en AHN., Estado, leg. 4309, caja 1, y otra en el leg. 4311, caja 2.

${ }^{12}$ La carta de Nicolás Bucareli y Ursúa al marqués de Grimaldi está fechada en Cádiz el 26 de julio de 1771 y se encuentra original en AHN., Estado, leg. 4309, caja 1.

${ }^{13}$ Véase la carta de Tomás Bremond al marqués de Grimaldi fechada en Larache el 30 de julio de 1771, que se halla original en AHN., Estado, leg. 4311, caja 2. 
David Cardoso, habida cuenta de las seguridades que da el cónsul Bremond ${ }^{14}$. De esta decisión se da cuenta al conde de Aranda, presidente del Consejo, "para noticia de la Suprema Junta de Sanidad, a fin de que se expidan por ella las órdenes que corresponde" 's.

Cuando el gobernador de Cádiz recibe la respuesta del marqués de Grimaldi, pasa "los correspondientes avisos» a la Junta de Sanidad de Cádiz y a Tomás Bremond "para que, inteligenciados den en la parte que les toca las providencias convenientes a su observancia" ${ }^{16}$. También ha recibido respuesta del marqués de Grimaldi el cónsul Tomás Bremond, comunicándole que serán admitidas las patentes de sanidad expedidas en la Mamora por David Cardoso Núñez. Bremond se da por enterado y promete proceder según se le ordena ${ }^{17}$.

Ignoro por cuánto tiempo estuvo el judío Cardoso expidiendo en la Mamora las patentes de sanidad a las embarcaciones españolas. En todo caso debió de cesar en este cometido lo más tarde a finales de 1774, al atacar el soberano marroquí la plaza de Melilla y declarar España la guerra a Marruecos, quedando interrumpida la comunicación entre los dos países ${ }^{18}$.

El convenio de Aranjuez, firmado en $1780^{19}$, restablece las rela-

${ }^{14}$ Según nota a continuación del extracto de la carta del gobernador de Cádiz del 26 de julio, citada en la nota 12, el marqués de Grimaldi le contestó en el sentido indicado en carta fechada en San Ildefonso el 12 de agosto de 1771.

${ }^{15} \mathrm{La}$ carta del marqués de Grimaldi al conde de Aranda está fechada en San Ildefonso el 12 de agosto de 1771. De ella tenemos una minuta en AHN., Estado, leg. 4309, caja 1 .

${ }^{16}$ De ello da cuenta Nicolás Bucareli y Ursúa al marqués de Grimaldi en carta fechada en Cádiz el 20 de agosto de 1771, que se conserva original en AHN., Estado, leg. 4309 , caja 1 .

17 Véase la carta de Tomás Bremond al marqués de Grimaldi fechada en Larache el 24 de septiembre de 1771, que se halla original en AHN., Estado, leg. 4311, caja 2.

18 Véase: V. Rodríguez CaSAdo, Politica marroquí, págs. 181- 203 y 205-249.

19 Texto publicado por M. Arribas Palau, «El texto árabe del convenio de Aranjuez de 1780", Tamuda VI (1958) 327-335. El texto castellano del mismo fue recogido por A. DEL CANTILlo, "Convenio de amistad y comercio entre el rey de España y el emperador de Marruecos, firmado en Aranjuez a 30 de Mayo de 1780", en su colección de Tratados, convenios y declaraciones de paz y de comercio que han hecho con las potencias extranjeras los monarcas españoles de la casa de Borbón desde el año 1700 hasta el día, Madrid 1843-1869, I, págs. 565-568. La versión francesa del convenio aparece en E. ROUARD DE CARD, Les relations de l'Espagne et du Maroc pendant le XVIII et le XIXe siècles, París 1905, documento $\mathrm{n}^{2} 2$ del Apéndice, págs. 175-179, recogida por J. CAILlE, Les accords internationaux du sultan Sidi Mohammed ben Abdallah (1757-1790), Tánger 1960, págs. 233-237. 
ciones entre España y Marruecos permitiendo que los españoles puedan efectuar libremente el comercio en los puertos marroquíes. Sin embargo, Carlos III resuelve centralizar la actividad comercial española en Tánger. A tal fin nombra cónsul general de España en Marruecos a Juan Manuel González Salmón, y no autoriza que se restituyan a sus anteriores destinos los vicecónsules de Tetuán, Jorge Patissiati, y de Tánger, Francisco Pacheco. Juan Manuel González Salmón deberá cuidar desde Tánger de ayudar a los españoles que vayan a Marruecos, "pero, como puede suceder que algunas embarcaciones» españolas arriben a los puertos de Mogador, Larache, Salé o Tetuán, el Rey quiere que González Salmón tenga en cada uno de estos puertos un confidente con la misión de dar al cónsul español "los avisos que puedan conducirle y proteja, en el mejor modo posible, los intereses de los nuestros». González Salmón podrá gratificar a estos confidentes "según viere que sirven y se conducen", incluyendo el importe de estas gratificaciones en su cuenta general de gastos ${ }^{20}$.

El primer ministro, conde de Floridablanca, informa al misionero franciscano Fr. José Boltas ${ }^{21}$ del nombramiento de Juan Manuel González Salmón como cónsul general en Marruecos y de las atribuciones que se le confieren. Entonces el P. Boltas recomienda a González Salmón que «trate con mucho pulso lo que se le previene sobre el nombramiento de comisionados en los puertos de estos payses que auxilien a nuestros nacionales». Por lo que respecta al

${ }^{20}$ Véase la carta que dirige el conde de Floridablanca a Juan Manuel González Salmón fechada en San Lorenzo el 28 de octubre de 1783, de la que tenemos una minuta en AHN., Estado, leg. 4317, caja 2. El conde de Floridablanca había sustituido al marqués de Grimaldi en el cargo de secretario del Despacho Universal y de Estado en febrero de 1777. Cf.: Gazeta de Madrid 8 (martes 25 de febrero de 1777) 71-72. Juan Manuel González Salmón fue nombrado cónsul general de España en Marruecos con residencia en Tánger, a finales de octubre de 1783. Anteriormente había estado encargado de los negocios de España en Marruecos. De su actuación se ocupa V. Rodríguez CaSAdo, Politica marroquí, págs. 335-372.

${ }^{21}$ De Fr. José Boltas, que posteriormente llegaría a ser obispo de Urgel, nos trazan una semblanza Fr. B. DifAz, "Ilmo. Sr. D. Fr. José Boltas", Mauritania IV (1928) 102-105, y Fr. M. R[OdRfGuez] Pazos, "Contribución a una monografía del Ilmo. P. Fr. José Boltas", Mauritania 206 (1945) 3-5. De la actuación de Fr. José Boltas en Marruecos se ocupa V. Rodriguez Casado, Politica marroqul, págs. 45-49, 258-284 y 307-334. Fr. José Boltas de Santa Bárbara era lector completo de sagrados cánones, guardián del real convento de la Purísima Concepción de Mequinez, viceprefecto apostólico y visitador general de las misiones del África tingitana. En esta forma se titula en un certificado expedido en Mequinez el 5 de enero de 1778, que se halla en AHN., Estado, leg. 5836. 
puerto de Larache, el $\mathrm{P}$. Boltas advierte que no hay en él ningún cristiano a quien se pueda confiar la comisión. En cuanto a los judíos, señala el P. Boltas que, "avn [cuando] no fueran tan embrollones y de mala fe como Vm. save, no son para el caso, por los desprecios y vltrages que generalmente padecen", incluso de los musulmanes «más viles, los quales no podemos evitar, ni es justo sufrir en vn comissionado de la nación". Por ello cree mejor el P. Boltas que se confíe el encargo a un musulmán ${ }^{22}$.

Teniendo en cuenta las indicaciones que le hacen el conde de Floridablanca y el P. Boltas en relación con el establecimiento de confidentes en los puertos marooquíes, Juan Manuel González Salmón se plantea el problema de Larache y dice al primer ministro español que en este puerto no hay de momento ningún negocio con los españoles. Ahora bien, en el supuesto de que por cualquier accidente llegase algún buque español al citado puerto, González Salmón asegura que tendría allí buena acogida, pues el gobernador de la ciudad se manifiesta "mui amigo» del cónsul español. Y éste añade: «al mismo tiempo, tengo correspondencia con vn [h]ebreo que reside en aquella plaza, quien, conservándolo propicio con alguna pequeña espreción (sic), me participará qualquier noticia que occurra". Sin embargo, en el caso de que más adelante hubiere en Larache algún comercio con los españoles, González Salmón se propone poner allí a un español, «si se encuentra a propósito", y en su defecto confiaría la comisión a un marroquí que le pareciera adecuado, ya que «los [h]ebreos, avn que tienen trastienda y son eficaces por lo que haze a dar avisos, no sirven para vna comissión de esta naturaleza, ni el genio de nuestros españoles se adapta ni conforma con el de ellos" ${ }^{23}$.

En mayo de 1784, Juan Manuel González Salmón comunicaba al conde de Floridablanca que el confidente de Larache le había escrito informándole de que el gobernador de esta ciudad tenía orden de permitir la extracción de refrescos, pagando los mismos derechos que en Tánger y en Tetuán. En consecuencia, el cónsul español ha pasado el aviso de esta novedad a los patrones de los

22 Véase la carta que dirige el padre Boltas a Juan Manuel González Salmón fechada en Mequinez el 21 de noviembre de 1783, de la que tenemos una copia en AHN., Estado, leg. 4317, caja 2.

${ }^{23}$ Véase la carta que dirige Juan Manuel González Salmón al conde de Floridablanca fechada en Tánger el 29 de noviembre de 1783, que se conserva original en AHN., Estado, leg. 4317, caja 2. 
barcos españoles de Cádiz, por si les resulta más práctico ir a Larache a hacer el tráfico de gallinas, como cree el cónsul que en efecto sucederá así, pues aquél es el paraje en que se crían estas aves en abundancia. Dice González Salmón que ya ha ido a Larache un falucho español para cargar gallinas. Este falucho ha sido bien asistido por el confidente hebreo y por el gobernador. Éste había prometido a González Salmón que proporcionaría a los españoles cuantos auxilios pudieran necesitar. Con todo, nuestro cónsul reitera su propósito de enviar a Larache "a vn europeo inteligente en las costumbres y trato de la gente del pays para que cuide de protexer a los nuestros y me dé los avisos que occurran", en el caso de que los españoles continúen frecuentando aquel puerto, como lo hacían antes de que se produjera el rompimiento entre España y Marruecos. Ahora bien, "si el tráfico no tomase cuerpo y sólo ba tal qual falucho, lo dexaré en el pie que se halla en el día, pues es sufissiente el confidente actual" ${ }^{24}$.

En octubre del mismo año 1784, expresaba Juan Manuel González Salmón al conde de Floridablanca lo muy satisfecho que estaba de los confidentes que tenía en los puertos de Larache y de Tetuán, tanto "por los puntuales avisos que me passan de todo quanto occurre" como por la asistencia que prestan a las embarcaciones españolas que arriban a los dos puertos mencionados.

David Cardoso Núñez había conseguido que pudiera salir de allí hacia Cádiz un falucho español cargado de gallinas, a pesar de hallarse en el puerto de Larache una galeota argelina, cuyo arráez se oponía a que saliera ningún barco, por temor a que diera aviso de su presencia en aquel puerto. Gracias a la «buena correspondencia» que mantenía el cónsul con el gobernador de Larache, le había escrito diciéndole que, si entraba allí algún buque argelino y se dirigía a aquel puerto alguna embarcación española, en cuanto ésta estuviera a la vista no permitiera salir a la nave argelina, obligándola a esperar veinticuatro horas en el caso de que las embarcaciones españolas decidieran salir al mar. Según los informes que ha ido dando Cardoso a González Salmón, el gobernador de Larache ha cumplido escrupulosamente estas instrucciones ${ }^{25}$.

${ }^{24}$ Véase la carta que dirige Juan Manuel González Salmón al conde de Floridablanca fechada en Tánger el 22 de mayo de 1784, cuyo original se encuentra en AHN., Estado, leg. 4317, caja 1.

${ }^{25}$ Véase la carta que dirige Juan Manuel González Salmón al conde de Floridablanca fechada en Tánger el 2 de octubre de 1784, que se halla original en AHN., Estado, leg. 4317, caja 1. 
Mientras tanto, por este mismo mes de octubre de 1784 una fragata marroquí apresa un bergantín americano y el monarca marroquí ordena al arráez Aḩmad Turkî, que manda la fragata, que lleve el bergantín al río de Larache y le da instrucciones sobre lo que debe hacer ${ }^{26}$. David Cardoso Núñez envía inmediatamente a Juan Manuel González Salmón una traducción castellana de la carta del soberano marroquí a Aḥmad Turki ${ }^{27}$. El cónsul español envía en el acto al conde de Floridablanca la traducción que le ha remitido Cardoso ${ }^{28}$.

En el mes de diciembre del mismo año 1784, David Cardoso da cuenta a Juan Manuel González Salmón de que en Larache se había avistado una barca grande argelina procedente del Estrecho, que dio caza a una pequeña saetía española ${ }^{29}$. Al recibir nuestro cónsul la noticia de la presencia en el Atlántico del buque pirata argelino, informó de ello a los comandantes de la costa y al de Ceuta, si bien las cartas no pudieron despacharse, por falta de buque español, hasta el 20 del citado mes de diciembre ${ }^{30}$.

Por agosto de 1786 comunica Cardoso a González Salmón que el español Ramón Ronda, que estaba en Larache con el pretexto de comprar gallinas por cuenta del comerciante Joaquín de Santiago y con destino al Hospital Real de Cádiz, se dedicaba a destilar y vender aguardiente públicamente. El cónsul español escribió entonces al gobernador de Tánger, Muhammad b. 'Abd al-Malik, para que hiciese expulsar de Larache a Ramón Ronda, lo que se ejecutó inmediatamente, obligándole a embarcarse para España.

${ }^{26}$ De este asunto me ocupo en M. Arribas PalaU, "Documentación española sobre las primeras relaciones entre Marruecos y los Estados Unidos de América del Norte", Hespéris-Tamuda XVII (1976-1977) 97-136. La traducción de la carta del sultán de Marruecos al arráez Ahmad Turkī que contiene estas instrucciones figura en la pág. 100.

${ }^{27}$ Así lo dice Juan Manuel González Salmón en carta que dirige al conde de Floridablanca el 11 de noviembre de 1784, citada en la nota siguiente.

${ }^{28}$ La carta que cursa Juan Manuel González Salmón al conde de Floridablanca enviándole la traducción que le ha remitido Cardoso está fechada en Tánger el 11 de noviembre de 1784 y ha sido publicada en M. ArRibas PalaU, "Documentación española", pág. 101.

29 La carta está fechada en Larache el 1 de diciembre de 1784 y se halla original en AHN., Estado, leg. 4317, caja 1.

30 Juan Manuel González Salmón informa de ello al conde de Floridablanca en carta fechada en Tánger el 31 de diciembre de 1784, que se encuentra original en AHN., Estado, leg. 4317, caja 1. 
Estima González Salmón que de ningún modo era conveniente que Ramón Ronda permaneciera en Marruecos, ya que «se empleaba en cosa que esta prohibida por el mismo Soberano, y que de ello se podrían accarrear muchas desazones y tal vez desgracias, padeciendo después toda la nación en general, como regularmente sucede quando algún yndividuo da escándalo o comete otro delito en el pays" ${ }^{31}$.

En las cuentas de gastos que presenta Juan Manuel González Salmón al conde de Floridablanca en los años 1784, 1785 y 1786, he encontrado algunas referencias a David Cardoso Núñez. Así, al anotar las "gratificaciones a los confidentes según el servicio que han hecho desde febrero de este año" 1784, se indica que al de Larache se le ha dado "en dinero efectivo" 600 reales de vellón y, "en chocolate", 80 "32. El 21 de julio de 1785 figura una partida de 24 reales de vellón abonados «a vn correo que me despachó David Cardoso desde Larache". Y en el mes de agosto siguiente se anota el pago de 2000 reales de vellón "por la gratificación de cien pesos fuertes hecha al [h]ebreo David Cardoso en Larache, como consta por su recibo adjunto no. 9. en atención a la asistencia que da a los españoles que ally concurren y avisos que me comunica, según le tengo prevenido" ${ }^{33}$.

En 1786 son más frecuentes las partidas de abono de cartas enviadas por David Cardoso Núñez: la primera figura anotada el día 13 de febrero por un importe de 2 onzas ${ }^{34}$; otra, el 2 de mayo,

${ }^{31}$ De ello da cuenta Juan Manuel González Salmón al conde de Floridablanca en su carta $n^{2}$ 104, fechada en Casablanca el 12 de agosto de 1786, que se halla original en AHN., Estado, leg. 4319, caja 1.

32 Esta partida figura al fol. $18 \mathrm{v}$. de la cuenta del cónsul español correspondiente a las fechas comprendidas entre el $1^{\circ}$ de noviembre de 1783 y octubre de 1784 . La partida que se cita está fechada el 26 de octubre de 1784. La cuenta se encuentra original en AHN., Estado, leg. 4346, caja 2.

${ }^{33}$ Estas dos partidas figuran al fol. 7 r. y 7 v. respectivamente de la cuenta de Juan Manuel González Salmón correspondiente a las fechas comprendidas entre el 10 de noviembre de 1784 y el 18 de octubre de 1785 . La cuenta se conserva original en AHN., Estado, leg. 4346, caja 2. El recibo de Cardoso lleva el $n^{2} 9$ y dice así: «Recevy de Don Juan Manuel Salmón, Cónsul General de España en los dominios marroquies la suma de cien pesos fuertes por vía de gratificaçión en consideraçión a la asistençia que doy a los españoles que bienen a este puerto y por my trabajo de otros encargos alusibos al servicio de la naçión española que me vienen ordenados por dicho sehor y para que conste donde convenga doy este presente resibo con un otro duplicado, ambos de vn mismo tenor y fecha, en Larache [a] 30 días del mes de Julio de 1785 David Cardoso Núnes [Rubricado]".

${ }^{34}$ Esta partida figura al fol. 3 v. de la cuenta de Juan Manuel González Salmón correspondiente a las fechas comprendidas entre el 14 de noviembre de 1785 y el 30 de octubre de 1786. Esta cuenta se halla original en AHN., Estado, leg. 4346, caja 2. 
por 1 onza ${ }^{35}$; la siguiente, el 31 también de mayo, por 1 onza ${ }^{36}$; el 28 de junio, otra por 1 onza ${ }^{37}$; el 12 de julio, otra por 2 onzas ${ }^{38}$; y finalmente, otra del 31 de julio, por 19 onzas ${ }^{39}$. La gratificación a David Cardoso Núñez, registrada con fecha 30 de octubre de 1786, asciende a 1200 reales de vellón ${ }^{40}$.

En marzo de 1787 cambia la actitud de Juan Manuel González Salmón respecto a los confidentes hebreos que tiene en los puertos de Larache y de Tetuán, pues la experiencia le ha demostrado que, "lexos de ser vtiles para la protección y asistencia que necesitan los barcos españoles que hacen tráfico a ambos puertos, son perjudiciales». En efecto, según González Salmón, estos confidentes "pueden prestar pocos o ningunos auxilios a los nacionales" y además se ha visto obligado a "sostenerlos a ellos mismos contra los insultos y tropelías del govierno (que, sin otro motivo más que por ser [h]ebreos, los miran con desprecio y vltrajan a cada instante)". Por ello ha recurrido el cónsul español al propio soberano marroquí, solicitando que cursara sus órdenes para que a estos confidentes hebreos los mirasen y tratasen los marroquíes "con el respeto correspondiente a la comisión que tienen». El sultán de Marruecos satisface en todas las ocasiones los deseos de González Salmón, "encargando fuertemente a los goviernos respectibos se atiendan y miren a estos sugetos como destinados" por el cónsul español para asistir a sus nacionales.

Esto ha originado otras dificultades, "porque los judíos, llebados del orgullo y soberbia que es proprio de esta nación quando se veen protegidos y en algún valimiento, confiados de mi sombra o abrigo, han pretendido (con particularidad el de Tetuán)» atropellar a algunos marroquíes, impidiéndoles "que tratasen y contratasen" directamente con los españoles y obligándoles a que tramitasen todos los negocios por su conducto. En la misma forma se dirigían a los patrones españoles, diciéndoles que tal era la "orden y disposissión" del cónsul de España.

Por todo ello, González Salmón toma la resolución de prescindir

\footnotetext{
${ }^{35}$ Ibidem, fol. $6 \mathrm{r}$.

${ }^{36}$ Ibidem, fol. $7 \mathrm{v}$.

${ }^{37}$ Ibidem, fol. $8 \mathrm{r}$.

38 Ibidem, fol. $8 \mathrm{v}$.

${ }^{39}$ Ibidem, fol. $9 \mathrm{r}$.

40 Ibidem, fol. 9 r.
} 
de los servicios de estos confidentes hebreos, ya que no los considera útiles más que para suministrar noticias, para lo cual son eficaces, como ha indicado en ocasiones anteriores, si bien este servicio de información lo puede conseguir igualmente por medio de "varios sugetos", sin necesidad de valerse precisamente de confidentes hebreos. Así, pues, González Salmón está decidido a poner en Larache a su intérprete José de la Cruz, a quien dará las instrucciones necesarias para su manejo ${ }^{41}$. El conde de Floridablanca aprueba lo dispuesto por el cónsul español ${ }^{42}$. Así terminan las funciones de David Cardoso Núñez en calidad de comisionado de Juan Manuel González Salmón en el puerto de Larache ${ }^{43}$.

A mediados de mayo de 1792 sale de Mogador el hāâŷy Ahmad al-Dalimî, que se dirige a Cádiz en calidad de embajador del príncipe marroquí Mawlāy Hišām ante la corte de España ${ }^{44}$.

El hāŷŷy Aḩmad al-Dalimì es portador de varias cartas escritas por David Cardoso Núñez, dirigidas a Juan Manuel González Salmón, y a su llegada a Cádiz a final de mayo son entregadas a su destinatario.

La primera de estas cartas está escrita de orden del hāâŷy Ahmad al-Dalimî, comunicando la llegada de éste a la bahía de Cádiz, su misión de embajador a la corte de España y que es portador de cartas del príncipe Mawlāy 'Abd al-Salām ${ }^{45}$ para González Salmón, que le entregará cuando se entrevisten y luego tratarán de su contenido ${ }^{46}$.

${ }^{41}$ Véase la carta $n^{\circ} 44$ de Juan Manuel González Salmón al conde de Floridablanca, fechada en Tánger el 20 de marzo de 1787, que se conserva original en AHN., Estado, leg. 5805.

${ }^{42}$ Véase la carta del conde de Floridablanca a Juan Manuel González Salmón fechada en Aranjuez el 15 de mayo de 1787, de la que tenemos una minuta en AHN., Estado, leg. 4319, caja 2.

${ }^{43}$ José de la Cruz fue destinado al puerto de Larache en noviembre de 1786, según recibo fechado en Larache a 22 de octubre de 1787, anexo a la cuenta de Juan Manuel González Salmón del 31 de octubre de 1787, que se halla original en AHN., Estado, leg. 4346, caja 2.

${ }^{44}$ De esta embajada me he ocupado en M. Arribas Palau, Una embajada marroquí enviada a España en 1792, Tetuán 1953; y en IDEM, "Nuevos datos sobre la embajada de Muhammad al-DaГimi (1792)", Tamuda II (1954) 9-32.

${ }^{45}$ Sobre este príncipe marroquí, véase: R. Lourido DíaZ, Marruecos en la segunda mitad del siglo XVIII. Madrid 1978, págs. 333-336.

46 Véase M. Arribas PalaU, "Nuevos datos", pág. 10. La carta no lleva fecha, pero sin duda la ha escrito Cardoso en Mogador el 17 de mayo de 1792. Se halla en AHN., Estado, leg. 4328, caja 2. 
La segunda carta la escribe Cardoso de orden del príncipe Mawlāy 'Abd al-Salām y tiene por objeto notificar a González Salmón que el príncipe pretendiente Mawlāy Hišām ha resuelto enviar al ḩâŷŷy A himad al-Dalimî, en calidad de embajador, a la corte de España y lo pone bajo la protección del propio González Salmón.

Aparte de esto, Mawlāy 'Abd al-Salām pide que se le envíe un buen oculista de Montpellier para que le trate su afección de la vista, que parece ser cataratas.

Finalmente Mawlāy 'Abd al-Salām pide a González Salmón que facilite al embajador al-Dalimî la conclusión de algunos encargos que tiene orden de comprar para el servicio del príncipe Mawlāy 'Abd al-Salām ${ }^{47}$.

La tercera carta la escribe Cardoso por su cuenta. En ella expone algunos antecedentes del embajador al-Dalimi y da cuenta de la situación en Marruecos, provincias bajo el mando de Mawlāy Hišām, providencias tomadas sobre el comercio en el puerto de Mogador y en el de Safi, derechos de entrada y de salida en ellos y comunica diversas noticias llegadas de Marrākuš ${ }^{48}$.

Cardoso escribe a González Salmón otra carta en la que le explica su decepción por no ir a Cádiz con el embajador al-Dalimî, pues esto le habría permitido poner en práctica su viejo proyecto de abrazar el catolicismo. Asegura que se le han proporcionado varios partidos para establecer una casa de comercio en Mogador o en Safi, pero no ha tomado ninguna decisión hasta recibir respuesta de González Salmón ${ }^{49}$. Éste cursa las citadas cartas al primer ministro español con sus consideraciones acerca de la inoportunidad de la embajada de al-Dalimī y la forma en que cree que podrá tratarse a éste ${ }^{50}$. Aparte remite la segunda carta de Cardoso, dando una serie de indicaciones acerca de su personalidad ${ }^{51}$.

47 Véase M. ARribas Palau, «Nuevos datos", págs. 11-12. La carta está fechada en Mogador el 17 de mayo de 1792 y se encuentra en AHN., Estado, leg. 4328, caja 2.

48 Véase M. Arribas Palau, "Nuevos datos», pág. 11. La carta está fechada en Mogador el 17 de mayo de 1792 y se conserva en AHN., Estado, leg. 4328, caja 2.

49 Esta carta de David Cardoso está fechada también én Mogador el 17 de mayo de 1792 y se halla igualmente en AHN., Estado, leg. 4328, caja 2.

50 Véase la carta $n^{2} 72$ de Juan Manuel González Salmón al conde de Aranda, fechada en Cádiz el 1 de junio de 1792, que se conserva original en AHN., Estado, leg. 4328, caja 2.

sl Esta carta de Juan Manuel González Salmón al conde de Aranda está fechada en Cádiz el 1 de junio de 1792, lleva el $n^{2} 73$ y se encuentra en AHN., Estado, leg. 4328, caja 2. 
A primeros de junio sale de Mogador un buque con destino a Cádiz. Mawlāy 'Abd al-Salām aprovecha esta oportunidad para ordenar a Cardoso que escriba a González Salmón reiterándole lo dicho en la carta del mes anterior que llevaba al-Dalimi ${ }^{52}$. David Cardoso cumple lo ordenado por Mawlāy 'Abd al-Salām y escribe a su vez a González Salmón, diciéndole que en Mogador se goza de la mayor tranquilidad y que el comercio manifiesta bastante vivacidad ${ }^{53}$.

Al regresar a Mogador el buque francés que ha llevado al hāŷŷ Ahmad al-Dāimì a Cádiz, Juan Manuel González Salmón contesta a Mawlāy 'Abd al-Salām expresándole la imposibilidad de recibir a al-Dalimi con carácter de embajador, pero que lo ha sido como particular de distinción ${ }^{54}$.

En la misma ocasión responde el cónsul español a las dos cartas de Cardoso del 17 de mayo y a la del 5 de junio. En su respuesta dice González Salmón que, de haber pasado Cardoso a Cádiz con Ahmad al-Dalimî, hubiera sido la ocasión más a propósito para efectuar su conversión y espera que tal vez en el futuro se le presente otra. Le agradece las noticias de Marruecos que le da "y sus buenos deseos de servirnos", de que hará uso cuando surja una oportunidad. Se refiere luego el cónsul a la carta que escribe a Mawlāy 'Abd al-Salām y encarga a Cardoso que "se la interprete bien" a fin de que el príncipe quede enterado de las razones que impiden por el momento admitir como embajador al hāŷŷ Ahmad al-Dalimî. Al mismo tiempo se interesa González Salmón por que Cardoso incline a Mawlāy 'Abd al-Salām a que contribuya para que su hermano Mawlāy Hišām actúe para hacerse reconocer en todo Marruecos o «se avenga a una composición amistosa con su hermano" Sulaymān ${ }^{55}$. De estas dos respuestas envía González Salmón una copia al conde de Aranda, explicándole las razones que le han

52 Esta carta de David Cardoso está fechada en Mogador el 5 de junio de 1792 y se halla en AHN., Estado, leg. 4328, caja 2.

53 Esta carta de David Cardoso está fechada en Mogador el mismo día 5 de junio de 1792 y se conserva en AHN., Estado, leg. 4328, caja 2.

54 Véase la carta de Juan Manuel González Salmón a Mawlāy 'Abd al-Salām fechada en Cádiz el 20 de junio de 1792, de la que tenemos una copia en AHN., Estado, leg. 4328, caja 2. El contenido de la carta queda recogido en M. ARRIBAS PalaU, "Nuevos datos sobre la embajada", págs. 16-17.

5s Esta carta de Juan Manuel González Salmón a David Cardoso está fechada en Cádiz el 20 de junio de 1792. De ella hay una copia en AHN., Estado, leg. 4328, caja 2. En esta ocasión remite el cónsul español a David Cardoso una lata de té, tres 
movido a contestar en la forma que lo ha hecho a Mawlāy 'Abd alSalām y a Cardoso.

También da cuenta González Salmón de las dos cartas que ha recibido de Cardoso, una escrita de orden de Mawlāy 'Abd alSalām y otra de su propia cuenta, en que le participa la tranquilidad que se disfruta en Mogador y el activo comercio que se realiza en aquel puerto, pero advierte el cónsul español que nada dice Cardoso de la situación actual de Mawlāy Hišām, aunque no espera que se muevan los ejércitos hasta final de mes, pues la gente que los compone está ocupada en recoger la cosecha ${ }^{56}$.

En los primeros días de julio acusa Cardoso el recibo de las cartas dirigidas por González Salmón al príncipe Mawlāy 'Abd alSalām y al propio Cardoso. Éste explica a González Salmón que tuvo buen cuidado de traducir a Mawlāy 'Abd al-Salām, palabra por palabra, la carta dirigida a él, de la cual «se tomó translado por escrivano de mucha confianza de Su Alteza", y que de las resultas dará cuenta dentro de poco ${ }^{57}$.

Avanzado el mes de agosto, Cardoso escribe de nuevo a González Salmón de orden de Mawlāy 'Abd al-Salām para que se ocupe de agenciar una embarcación que sirva para conducir cartas desde Agadir y Mogador, por toda la costa marroquí, hasta Tánger. También ofrece Mawlāy 'Abd al-Salām el puerto de Agadir para la pesca de los marineros canarios y para el comercio de maíz, cera "o qualquiera otro producto" con destino a las islas Canarias, al que se aplicará un derecho de exportación moderado. Avisa Cardoso que Mawlāy 'Abd al-Salām va a marchar a Agadir, que el mismo

pilones de azúcar, ocho libras de chocolate y un barrilito de vino de Málaga. A Mawlāy 'Abd al-Salām le envía González Salmón un sable y varios efeqtos. El contenido de esta carta de González Salmón a David Cardoso queda recogido en M. ARribas PALAU, "Nuevos datos sobre la embajada", págs. 17-19.

56 Véase la carta $n^{0} 85$ de Juan Manuel González Salmón al conde de Aranda, fechada en Cádiz el 22 de junio de 1792, que se encuentra original en AHN., Estado, leg. 4328, caja 2. En ella dice el cónsul español que David Cardoso "nació en Gibraltar, haviendo sido su padre vno de los comerciantes más acaudalados de dicha plaza, y poseyendo el árabe, ynglés, francés y español con propriedad, se estableció en Marruecos, en donde se ha manejado con buena conducta, haviendome confiado sus vivos deseos de trasladarse a España con el ánimo de hazerse cathólico, en los que persiste, según se explica en la citada carta".

57 Esta carta de David Cardoso está fechada en Mogador el 3 de julio de 1792 y se halla en AHN., Estado, leg. 4328, caja 2. 
Cardoso debe formar parte de la comitiva, y da instrucciones para el curso posterior de la correspondencia ${ }^{58}$.

A finales del mismo mes de agosto escribe David Cardoso una larga carta a Juan Manuel González Salmón. En ella le comunica que Mawlāy 'Abd al-Salām había partido ya hacia Agadir, pero que él se había detenido en Mogador unos días por hallarse indispuesto, aunque en breve debía ponerse en camino para reunirse con Mawlāy 'Abd al-Salām. Y a continuación da una serie de noticias relativas a la situación en la parte meridional de Marruecos ${ }^{59}$.

Mientras tanto, el embajador hāŷŷy Ahmad al-Da「imỉ había marchado de Cádiz y había desembarcado en Larache, poniéndose a las órdenes de Mawlāy Sulaymān. Como podría pensar Mawlāy 'Abd al-Salām que en ello había tenido parte España, González Salmón escribe a David Cardoso Núñez informándole de las circunstancias en que había salido al-Dalimì de Cádiz y señalando que la decisión de desembarcar en Larache correspondía exclusivamente a al-Dalimi, sin que en ella hubiera tenido nada que ver España, como podía comprobarse por la contrata firmada con el capitán del bergantín en que viajaba el citado al-Dalimì, en la cual se especificaba que éste debía desembarcar en Mazagán, en Safi o en Mogador, a su elección ${ }^{60}$.

En el mes de octubre se recibe en Cádiz una carta anónima de Mogador en que se hace referencia a la mala impresión que ha

${ }^{58}$ Esta carta de David Cardoso está fechada en Mogador el 24 de agosto de 1792. Juan Manuel González Salmón envía al conde de Aranda la carta de Cardoso anexa a su escrito $\mathrm{n}^{2} 124$, fechado en Cádiz el 21 de septiembre de 1792, que se conserva original en AHN., Estado, leg. 4328, caja 2.

59 La carta de David Cardoso está fechada en Mogador el 29 de agosto de 1792. De ella tenemos una copia en AHN., Estado, leg. 4327, caja 1. Juan Manuel González Salmón envía esta carta de Cardoso al conde de Aranda anexa a su escrito $n^{2} 124$, citado en la nota anterior.

60 Esta carta de Juan Manuel González Salmón a David Cardoso está fechada en Cádiz el 7 de septiembre de 1792. De ella hay una minuta en AHN., Estado, leg. 4327, caja 1. El cónsul español escribe también en forma similar al alcaide Dris y al canciller del consulado de Francia en Salé, Mure de Pelanne. Véase la carta $n^{\circ} 122$ de Juan Manuel González Salmón al conde de Aranda, fechada en Cádiz el 7 de septiembre de 1792. Al alcaide Dris he dedicado una comunicación, M. ARRIBaS PalAU, "El alcaide Dris", en Atti del I Congresso Internazionale di Studi NordAfricani 1965, (Cagliari, 22-25 enero 1965), Cagliari 1969, págs. 139-146. Del canciller Mure de Pelanne me ocupo en M. ARribas PalAU, "La ayuda prestada a España por el canciller Mure de Pelanne en 1791 y 1792", en Actes du II Congrès International d'Études Nord-Africaines, (Aix-en-Provence 27-29 noviembre 1968), Aix-en-Provence 1970, págs. 31-44. 
causado el trato dado al ḩāŷy Aḥmad al-Dalimin y a la carestía de dinero en la zona que reconoce a Mawlāy Hišām, para solucionar la cual se va a reunir una partida de unas 300.000 fanegas de trigo, que se centralizará en Mazagán, desde donde se enviará a Cádiz a fin de reducirla a dinero. El comprador de la partida parece que será el comerciante genovés José Chiappe. En tal caso, nada deberían agradecer a España ${ }^{61}$.

Ya hemos visto que David Cardoso se disponía a partir hacia Agadir. Desde esta ciudad escribe a Juan Manuel González Salmón, de orden de Mawlāy 'Abd al-Salām, para asegurarle que los españoles serán bien recibidos en la costa atlántica marroquí comprendida entre Mazagán y Agadir y que los comerciantes de las islas Canarias pueden acudir al puerto de Agadir para cargar maíz, cera, aceite y los demás productos del país ${ }^{62}$.

Juan Manuel González Salmón agradece los ofrecimientos de Mawlāy 'Abd al-Salām, pero expone a Cardoso las dificultades que se presentan para hacer uso de ellos, pues esto sería señal de que España reconocía a Mawlāy Hišām como soberano de Marruecos, cuando hay otro hermano, Mawlāy Sulaymān, que pretende dicha soberanía. Por ello Carlos IV quiere mantener una estricta neutralidad, lo que le impide comerciar con ninguno de los príncipes pretendientes al trono de Marruecos. También manifiesta González Salmón a Cardoso que no había podido encontrar en Cádiz la embarcación que le había encargado Mawlāy 'Abd al-Salām ${ }^{63}$.

Cardoso contesta a esta carta a mediados de febrero de 1793, diciendo que había presentado el escrito de González Salmón al príncipe Mawlāy 'Abd al-Salām. Éste reitera su oferta de los puertos de Agadir y Mogador a los comerciantes españoles, sin que por ello

${ }^{61}$ Esta carta anónima es atribuida a David Cardoso. Juan Manuel González Salmón la envía al conde de Aranda anexa a su carta ne 130, fechada en Cádiz el 26 de octubre de 1792, que se halla original en AHN., Estado, leg. 4328, caja 2.

${ }^{62}$ Esta carta de David Cardoso está fechada en Santa Cruz de Berbería (= Agadir) el 3 de octubre de 1792. Juan Manuel González Salmón la envía al duque de la Alcudia anexa a su escrito $n^{2} 148$, fechado en Cádiz el 11 de diciembre de 1792, que se encuentra original en AHN., Estado, leg. 4328, caja 2. Manuel Godoy, duque de la Alcudia, había sustituido al conde de Aranda en el cargo de primer secretario de Estado y del Despacho en noviembre de 1792. Véase la Gazeta de Madrid 93, (martes 20 de noviembre de 1792) 817.

${ }^{63}$ Esta carta de Juan Manuel González Salmón a David Cardoso está fechada en Cádiz el 21 de diciembre de 1792. De ella hay una copia en AHN., Estado, leg. 4330, caja 2. 
se pueda considerar agraviado ninguno de los dos pretendientes al trono marroquí. Considera que puede efectuarse la adquisición de cera, artículo que se consume en Cádiz y en Canarias en gran cantidad. Los españoles serían entonces preferidos y se les reservaría la exclusiva, abonando un derecho de siete pesos fuertes por quintal, en lugar de los diez que se exigen a las demás naciones. Y el derecho de extracción del aceite quedaría reducido a la mitad del que abonan los demás comerciantes ${ }^{64}$.

Por entonces Francia declara la guerra a España y ésta modifica su actitud para con los príncipes marroquíes, manteniendo la rigurosa neutralidad, pero comerciando indistintamente con los puertos sometidos a uno y otro pretendiente. Así, pues, González Salmón puede asegurar a David Cardoso que va a hacer "los mayores esfuerzos para inclinar la voluntad del Rey mi amo" a que acepte las propuestas de Mawlāy 'Abd al-Salām, lo que espera conseguir. Por ello cree que dentro de poco se verán embarcaciones españolas en Agadir. Y pide a Cardoso que le dé noticia de las mercancías que se pueden extraer por el mencionado puerto de Agadir y de las españolas que tengan fácil salida en dicho puerto. También le solicita una relación de los derechos que se abonan a la introducción y a la extracción de estos productos, preguntando si se podrá contar con alguna partida de trigo, de legumbres y de carne y si el puerto de Agadir es más o menos adecuado que el de Mogador para el tráfico comercial con las islas Canarias ${ }^{65}$.

En los primeros días de mayo de 1793, Juan Manuel González Salmón comunica a Mawlāy 'Abd al-Salām que el rey de España ha querido dar una nueva prueba al citado Mawlāy 'Abd al-Salām y a sus hermanos Mawlāy Hišām y Mawlāy Sulaymān de la confianza que le merecen sus ofertas y las órdenes expedidas a los gobernadores de los puertos en favor de los españoles, por lo cual ha autorizado a los súbditos españoles para que vayan a traficar a Marruecos, así como se autoriza a los súbditos marroquíes para que pasen a los puertos españoles "en los mismos términos que lo executaban en el reynado del defunto buen rey Sid Mohamet Ben-Abdallá». También

${ }^{64}$ Esta carta de Cardoso a González Salmón esta fechada en Santa Cruz de Berbería (= Agadir) el 15 de febrero de 1793, y se halla original en AHN., Estado, leg. 4330, caja 2.

${ }^{65}$ Esta carta de González Salmón a Cardoso está fechada en Cádiz el 5 de abril de 1793. De ella tenemos una copia en AHN., Estado, leg. 4330, caja 2. 
se expedirán las órdenes oportunas a las islas Canarias para que se reanude el tráfico con los puertos marroquíes y la pesca en sus aguas, como lo hacían antes ${ }^{66}$.

Esta carta la envía González Salmón a David Cardoso para que explique su contenido a Mawlāy 'Abd al-Salām "con la perfección que acostumbra y es necesaria». Pero advierte a Cardoso que las mismas ofertas que éste le ha hecho de orden de Mawlāy 'Abd alSalām las ha hecho el musulmán Muhammad "Skyrge», antes Eliyahu ha-Leví, hebreo, al comerciante Benito Patrón. Por ello llama su atención sobre la gran diferencia que existe entre hacerle las ofertas a él, como empleado del Rey, pues así "se hazen a toda la nación española", y hacérselas a un particular ${ }^{67}$.

Cuando estas cartas llegan a Agadir, Mawlāy 'Abd al-Salām había marchado de esta ciudad y se había dirigido a Fez para reunirse con su hermano Mawlāy Sulaymān. En Agadir ha quedado en funciones de gobernador Mawlāy 'Abd al-Malik, hijo de Mawlāy 'Abd al-Salām, el cual, enterado del contenido de la carta destinada a su padre, aseguró a Cardoso que dicho Mawlāy 'Abd al-Salām «le había dexado particular encargo para que tratasse con aprecio y distinción a la nación española». Así, pues, decidió escribir él mismo a González Salmón, mandando a Cardoso con los pliegos a Mogador y ordenándole que permaneciera allí hasta que llegara la respuesta del cónsul español. Además, Mawlāy 'Abd al-Malik encarga a Cardoso el cobro de diversas cantidades que una casa comercial de Cádiz adeuda a varios judíos de Mogador ${ }^{68}$.

A mediados de agosto escribe nuevamente Cardoso a Juan Manuel González Salmón, sin haber recibido respuesta a su carta anterior, de la que envía un duplicado. En esta ocasión da Cardoso informes muy precisos acerca de la situación en Marruecos. Mawlāy 'Abd al-Malik se queja de que los españoles no aparezcan por Agadir ni tampoco los de las islas Canarias, y comunica que su padre le reitera en todas sus cartas que cuide y atienda a la nación

${ }^{66}$ Esta carta de Juan Manuel González Salmón a Mawlāy 'Abd al-Salām está fechada en Cádiz el 3 de mayo de 1793. De ella tenemos una copia en AHN., Estado, leg. 4330 , caja 2.

${ }^{67}$ Esta carta de González Salmón a Cardoso está fechada en Cádiz el 3 de mayo de 1793. De ella hay una minuta en AHN., Estado, leg. 4330, caja 2.

${ }^{68}$ No he encontrado la carta original de Cardoso, fechada en Mogador el 14 de junio de 1793, pero sí un extracto de ella y de otras dos posteriores hecho por González Salmón, que puede consultarse en AHN., Estado, leg. 5808. 
española. Avisa Cardoso la llegada a Agadir de una embarcación sueca procedente de Cádiz y comunica que él no se decide a volver a Agadir sin haber recibido las respuestas de González Salmón ${ }^{69}$. Unos días después comunica Cardoso la actividad desplegada por Mawlāy Hišām para afianzar su dominación ${ }^{70}$.

El comercio con Marruecos se concede a los cinco gremios mayores de Madrid ". Los directores de los gremios se disponen a realizar un ensayo en Agadir y para eso comisionan a los directores del establecimiento en Cádiz, los cuales deberán concertar con González Salmón «el modo y tiempo en que han de hacer la primera expedición" "2. Los directores de los gremios en Cádiz solicitan del cónsul español que, como se trataba de enviar un buque a Agadir "con el sujeto que debía establecerse allí, les hiziese favor de nombrar" una persona de su confianza "para que a los principios dirigiese a el que va de España». Entonces González Salmón avisa a David Cardoso, que estaba en Mogador, para que pase al puerto de Agadir, ya que en fecha próxima debía llegar a dicho puerto el comisionado de los cinco gremios para iniciar su comercio allí.

Cardoso marchó inmediatamente a Agadir, pero en junio de 1794 «se lamenta fuertemente de la demora y gastos que le ha causado el viaje y ocasiona su manutención allí», a la vez que expresa la impaciencia de Mawlāy 'Abd al-Malik por el retraso en la llegada del esperado buque mercante español. En vista de ello González Salmón escribe a los directores de los cinco gremios en Madrid para que decidan si les interesa o no el comercio en Agadir, a fin de comunicar su decisión a Mawlāy 'Abd al-Malik ${ }^{73}$.

Los directores de los cinco gremios mayores de Madrid contestan

${ }^{69}$ El contenido de esta carta, fechada el 16 de agosto de 1793, queda reflejado en el extracto que hace González Salmón, citado en la nota anterior.

${ }^{70}$ Esta carta de Cardoso está fechada el 24 de agosto de 1793. Su contenido queda reflejado al final del extracto que hace González Salmón, citado en la nota 68.

${ }^{71}$ De estos gremios se ocupan M. Capilla y A. Matilla Tascón, los cinco gremios mayores de Madrid, Madrid 1957. En la pág. 269 comienza el libro IV, que tiene por objeto la "Expansión y actividad de los cinco gremios en Europa y Ultramar»; el comercio con Marruecos es tratado en las págs. 278-283.

${ }^{72}$ Así lo dice el duque de la Alcudia a Juan Manuel González Salmón en carta fechada en San Lorenzo el 17 de diciembre de 1793, que se conserva original en AHN., Estado, leg. 4331, caja 1.

${ }^{73}$ De todo ello da cuenta Juan Manuel González Salmón al duque de la Alcudia en su carta $n^{2} 113$, fechada en Cádiz el 15 de julio de 1794, que se encuentra original en AHN., Estado, leg. 4331, caja 2. 
a González Salmón diciéndole que han pasado sus instrucciones a los directores de la casa que tienen en Cádiz "para que a la mayor brevedad se practicase el primer ensayo". Estos directores de Cádiz avisan al cónsul español que «tienen ya sujeto destinado y que en breve marchará a aquel puerto" de Agadir ${ }^{74}$.

A finales de diciembre del mismo año 1794 , los directores de los cinco gremios mayores de Madrid exponen al duque de la Alcudia que el año anterior se había tratado de la expedición de un buque a Agadir por vía de ensayo. Los gremios, para realizar este ensayo "sin aventurar los fondos a vn inminente peligro de malversación", propusieron que previamente se ajustara con Mawlāy 'Abd al-Malik "vna partida considerable de trigo». Esta partida debía estar preparada en Agadir para cargarla en el buque que se destinara a efectuar el ensayo. La partida debía aprontarse «a precio alzado, con inclusión de todos los derechos». Además, debían pedirse "muestras de los granos y razón de su existencia, para fletar la embarcación al primer aviso".

El cónsul español no cumplió lo que se le pedía, proponiendo, en cambio, la formación de un establecimiento «a su arbitrio» en Agadir, que debía dedicarse "a negociaciones de diversa clase y de corta o ninguna importancia». Con esta idea, González Salmón escribió a los directores de los gremios enviándoles una carta de Mawlāy 'Abd al-Malik, otra de Mawlāy 'Abd al-Salām y una tercera de su corresponsal en Agadir, David Cardoso, "reducidas a instar por la plantificación de [la] factoría española». En lugar de tratar de la preparación de algún cargamento de trigo, los gremios se encontraron "con vna nota o factura simulada del coste de cierta pequeña especulación de mulas». Por otra parte, el hebreo Cardoso relataba el hecho de que una barca gaditana de porte de 700 quintales no pudo emplear en dicho puerto de Agadir "quatro mil pesos fuertes, que era todo su caudal, por falta de frutos en que invertirlo». Esto desengañó a los directores de los cinco gremios, los cuales avisaron a González Salmón de que renunciaban al proyecto por considerarlo «absolutamente contrario a la buena administración".

Dadas las dificultades que ofrece el comercio con Europa, los

74 Juan Manuel González Salmón informa debidamente de ello al duque de la Alcudia en su carta $n^{9} 120$, fechada en Cádiz el 1 de agosto de 1794, que se halla original en AHN., Estado, leg. 4331, caja 1. 
gremios consideran que les es indispensable acudir a las costas de Africa "para la exportación de los surtidos». Por ello se deciden a abrazar "la exclusiba de los puertos de Darbeyda [= Casablanca], Larache, Saffy, Mazagán" y otros luego que Mawlāy Sulaymān "ofreció preferir en ellos a la vandera española en obsequio de S.M.». Con este objeto los gremios redactan un plan y nombran a un encargado particular suyo para los negocios de comercio, que debe pasar a Marruecos en cuanto Carlos IV lo autorice, llevando los correspondientes despachos de recomendación para Mawlāy Sulaymān y sus ministros, con absoluta independencia del cónsul Juan Manuel González Salmón para los citados asuntos de comercio ${ }^{75}$.

El duque de la Alcudia comunica a los gremios, en respuesta a su representación, que el monarca español ha aceptado su plan de comercio en Marruecos y que la primera Secretaría de Estado proporcionaría al comisionado'de los gremios «los despachos convenientes habilitándole para tratar con el príncipe Muley Soliman, con independencia del Consulado general, sobre la extracción de granos", pero con la advertencia al comisionado de que «sus pasos en aquel Reyno no compliquen los asuntos de comercio de granos [...] con los methódicos y amistosos de la paz en que vivimos con él, comprometiendo al Ministerio o perjudicando directa o indirectamente a las demás negociaciones políticas que éste siga o entable con el de dicho príncipe en la oportunidad" ${ }^{76}$.

Suprimida así la intervención del cónsul español en los asuntos comerciales, no aparece ya más correspondencia con David Cardoso Núñez en la documentación que he manejado.

75 Véase la carta de los directores de los cinco gremios al duque de la Alcudia fechada en Madrid el 30 de diciembre de 1794, que se conserva original en AHN., Estado, leg. 5808.

${ }^{76}$ Véase la carta del duque de la Alcudia a los directores de los cinco gremios fechada el 4 de enero de 1795, de la que tenemos una minuta en AHN., Estado, leg. 5808 . 


\title{
RESUMEN
}

En este artículo se recoge la correspondencia del judío David Cardoso Núñez, primero con el cónsul de España en Larache, Tomás Bremond, y luego con el cónsul español en Tánger, Juan Manuel González Salmón. Bremond comisionó a Cardoso para que expidiera las patentes de sanidad a las embarcaciones españolas que fueran al puerto de la Mamora. González Salmón eligió a Cardoso como confidente en Larache, cargo que desempeñó desde finales de 1783 hasta octubre de 1787. Más tarde, en 1792, Cardoso escribe a González Salmón en nombre propio, en el del embajador Ahmad al-Dalimì y en el del príncipe Mawlāy 'Abd al-Salām, lo que origina la correspondencia que aquí presentamos.

\begin{abstract}
This article compiles the letters exchanged between the Jewish David Cardoso Núñez and the Spanish Consul in Larache, Tomás Bremond, first, and the Spanish Consul in Tangiers, Juan Manuel González Salmón, then. Bremond gave Cardoso the job of issuing the health certificates for the Spanish ships which would sail to La Mamora harbour. González Salmón chose Cardoso as his information supplier in Larache, since the end of 1783 until October 1787. Later on, in 1792, Cardoso writes to González Salmón on behalf of himself, the Ambassador Ahmad al-Dalimi and the Prince Mawlāy 'Abd al-Salām. This generates the mail presented in this article.
\end{abstract}

